\title{
Impact of Specialized Goat Training Programme on Knowledge Level of Farmers - A Review
}

\author{
Khushpreet Singh $^{1 *}$, Ravdeep Singh ${ }^{1}$, Rajesh Kasrija ${ }^{1}$, Kulvinder Singh ${ }^{1}$, \\ S. K. Kansal ${ }^{1}$ and H. K. Verma ${ }^{2}$ \\ ${ }^{1}$ Department of Veterinary \& Animal Husbandry Extension Education, Guru Angad Dev \\ Veterinary and Animal Sciences University, Ludhiana, India \\ ${ }^{2}$ Director Extension Education, Guru Angad Dev Veterinary and Animal Sciences University, \\ Ludhiana, India \\ *Corresponding author
}

\begin{abstract}
A B S T R A C T
Goats are among the main meat producing animals in India. Along with chevon, goats also provide other products like milk, skin, fibre and manure. Increasing demand for chevon and goat milk has attracted majority of the farmers towards goat farming. Multipurpose potential with good economic returns has encouraged the educated youth, ladies, businessmen and progressive farmers to take up the goat enterprise on a commercial scale. Goat farming in India has low productivity which may be attributed to the lack of scientific knowledge. Training programmes are a source to bridge the gap between management practices followed by the farmers and the available scientific technologies. Keeping this in view, the impact of training programmes on knowledge gain of goat farmers was studied. Suitable duration of goat training programme is must for desired results. The frequencies of short duration training programmes should be increased to benefit goat farmers. Knowledge level of farmers towards goat farming was low and there was a significant improvement in their knowledge after attending training on various aspects of goat rearing. The knowledge of respondents was found enriched in various management practices. Specialized training programmes are playing an important role for knowledge up gradation and hence improving the socio-economic conditions of the goat farmers. Lack of knowledge was one of the main factors restraining in adoption of scientific goat farming. The scientific knowledge about any enterprise is crucial for its success. Regular need based specialized goat training programmes must be offered to update farmers with latest technologies.
\end{abstract}

\section{Introduction}

Goat farming is one of the important enterprises that support the rural households by providing gainful employment and steady income. Quick return on account of short generation intervals, higher rate of prolificacy and marketing of related products can be done 
easily at any time. Raising goats either for backyard farming or for commercial scale is cheaper and profitable than other livestock farming enterprise. Increasing demand for chevon and goat milk has attracted majority of the farmers towards goat farming. Multipurpose potential with good economic returns has encouraged the educated youth, ladies, businessmen and progressive farmers to take up the goat enterprise on a commercial scale. On the other hand, goat farming in India has low productivity which may be attributed to the lack of scientific knowledge (Landge, 2004). Studies conducted so far reported that there is gap between the improved and existing practices of goat rearing which resulted in poor production performance of the animals (Mohan et al., 2009). Training and development leads to improved profitability and more positive attitudes towards profit orientation (Singh, 2012).

Specialized goat training programmes are desirable to farmers as they are often eager to improve their knowledge and practices and to have their knowledge affirmed by professionals. Training is an integral and crucial input for the human resources development in all walks of life and to bring out desirable changes in human behaviour (Biswas et al., 2008). Training programmes are a source to bridge the gap between management practices followed by the farmers and the available scientific technologies. These training programmes not only help to improve efficiency of farmers by educating them how they can use available resources in most efficient and balanced way but also provide a roadmap to the farmers through introducing them with latest technologies who want to adopt goat farming. Training is a learning process that involves the acquisition of knowledge, sharpening of skills and concepts to enhance the performance. Training is activity leading to skilled behavior. Training is about knowing where you stand (no matter how good or bad the current situation looks) at present, and where you will be after some point of time. $78 \%$ of the respondents were of the opinion that training and development helps in increasing the knowledge and skills (Singh, 2012).

Suitable duration of goat training programme is must for desired results. Dixit et al., (2014) suggests that the frequencies of short duration training (5 and 10 days) programmes should be increased to benefit goat farmers. Goat farmers were imparted five days training on goat farming through lectures, presentations, demonstrations and visits (Hundal et al., 2016). Five day specialized goat training programmes enable farmers to increase their knowledge level and adoption (Singh et al., 2019). Success of such trainings will be dictated by the perceived effectiveness whether these training improve farmer's knowledge about technical aspects of goat farming.

The impact of the training programme on the knowledge level of farmers was assessed through taking knowledge test before and after training programme. Five questions of different levels from each area viz. goat breeding, feeding, health, housing and reproduction were asked. The course content (theory and practical) consisted of knowledge regarding breeds, sheds, deworming, vaccination, diseases (bacterial, viral and protozoal), reproductive problems, balanced ration, laboratory tests, management of kids, value added products, handling, first aid, preventive measures, economics of farm, loan facility, marketing and various other managemental practices. Scores were calculated for pre and post knowledge test (Singh et al., 2019). Education level of the farmers can also affect the gain in knowledge. $17.6 \%, 31.2 \%$ and $42.4 \%$ respondents were 
educated upto middle, matric and senior secondary level, respectively whereas $8.8 \%$ trainees were graduates (Hundal et al., 2016). The average knowledge scores increased from $3.63 \pm 0.16$ to $7.71 \pm 0.72$ (Singh et al., 2018) and from $3.58 \pm 0.13$ to $7.67 \pm 0.09$ indicating high knowledge gain. Knowledge level of farmers towards goat farming was low and there was a significant $(\mathrm{P}<0.05)$ improvement in their knowledge after attending five days training on various aspects of goat rearing (Singh et al., 2019) .

Impact of training programmes on the knowledge of the trainees participated under national and sponsored training programme on scientific goat farming at Central Institute for Research on Goats (CIRG) was studied by Dixit et al., (2014). Average knowledge scores have been calculated for the participants of four national (10 days) and four sponsored training programme (5 days) through pre and post examination In 10 days training programmes of four trainings the the average knowledge scores increased from 11.9 to $22.7,6.6$ to $21.71,7.94$ to 21.25 and 7.06 to 22.80 indicated that there was significant gain in the knowledge of participants on scientific goat farming. CIRG also conducted 4 sponsored training programmes (5 days each) for goat farmers from the states namely Bihar and Himachal Pradesh. The average knowledge scores of participants before and after training were 6.37 to $20.21,5.41$ to $20.67,5.84$ to 18.74 and 4.20 to 19.80 . The' $t$ ' value clearly indicated that there was a significant improvement in the knowledge of goat farmers on different aspects of improved goat rearing. Maximum gain was observed in the average knowledge scores of participants from Nauni, Solan district of Himachal Pradesh (Dixit et al., 2014).

Hundal et al., (2016) found that before training, only $2.4 \%$ of the farmers belonged to high level knowledge category while $76.8 \%$ $(\mathrm{P}<0.01)$ of farmers possessed high level knowledge after training. The awareness perceived by farmers about feeding, reproduction and disease management was significantly $(\mathrm{P}<0.05)$ higher after training. About, $11.4 \pm 0.16$ and $21.6 \pm 0.18$ responses of farmers were found to be correct during preand post-training, respectively which may be due to the effect of training on their knowledge level. Vidya et al., (2010) also reported pre- and post- exposure mean scores of 7.98 and 14.91, respectively. Age and education have no significant affect on increase in correct responses regarding knowledge level of farmers about goat farming (Hundal et al., 2016). These findings are contrary to the findings of Patil et al., (2009) who found a positive and significant relationship between education and correct responses of the farmers. Noor and Doha, (2011) also concluded that training had positive impact to the farmer's perception and performance. Biswas et al., (2008) also reported that there was a significant difference in knowledge of respondents of deworming and vaccination as a result of training.

The respondents knowledge was found enriched in the management practices like deworming of goats $(60 \%)$, feeding of colostrums to kids $(60 \%)$ and use of vaccine like PPR, ET, FMD etc. (56.7 \%) (Mandavakar et al., 2015). The farmers had gained $73.0 \%$ knowledge in housing, $73.5 \%$ in breed awareness, $72.5 \%$ in vaccination, $70.0 \%$ in deworming, $70.0 \%$ in fodder production, $60.5 \%$ in concentrate feed and 49.7\% in Mineral mixture (Senthilkumar et al., 2014). The overall mean knowledge score at pre and post exposure stages were 4.70 and 22.51 with difference of knowledge gain showing 17.81 (59.36\%). The descending order of knowledge gain among various aspects was fodder production (70.36\%), 
health care management $(61.33 \%)$, housing management $(60.60 \%)$, feeding practices $(51.60 \%)$, breeds and breeding management $(59.26 \%)$ and general care and management (53.06\%) (Belakeri, et al., 2017).

Specialized goat training programme is an effective tool to improve knowledge. The reason for higher knowledge of the trained respondents might be due to appropriateness of the syllabus covered and exposure visits at goat farms. Farmers showed great interest towards the various practicals conducted especially handling, first aid, preventive measures and value addition. Opportunity to discuss the doubts with subject matter specialists may be another possible reason for their improved knowledge level. $88.13 \%$ of the farmers suggested for conducting research programmes to increase milk production by developing crossbred goats and value added products for financial profitability (Singh et al., 2018). Training program had a tremendous impact in terms of knowledge gain on scientific practices of goat rearing. The recent trend in livestock sector growth suggests that in order to meet the emerging demand for livestock meat and its products, both in domestic and global markets, there is a need to reorient the production system by imparting scientific rearing practices. Training played the crucial role and it is recommended that strengthening of extension professionals and training system has to be done for taking up more training programmes to make the farmers knowledge rich, which in turn leads to adoption of scientific rearing practices (Belakeri et al., 2017). Lack of knowledge is one of the main factors restraining in adoption of scientific goat farming (Mohan et al., 2009). The scientific knowledge about any enterprise is crucial for its success. Hence, regular need based specialized goat training programmes must be offered to update farmers with latest technologies.

\section{References}

Belakeri, P., Mohankumar, S., Shankarappa, B. and Nishath, C. 2017. Effectiveness of Sheep and Goat Training Programme in terms of Knowledge Gain among Livestock Farmers of Karnataka Int. J. Pure App. Biosci. 5 (1): 31-34.

Biswas, S., Sarkar, A. and Goswami, A. 2008. Impact of KVK training on Advance Dairy Farming Practices (AFDPS) in changing knowledge and attitude of Prani-Bandhu. J. Dairying, Foods \& Home Sci. 27(1): 43-46.

Dixit, A. K., Mohan, B., Singh, K. and Kumar, V. 2014. Impact of Training Programme on Goat Farmers and Stakeholders: A Study of CIRG Training Programmes. Indian Res. J. Ext. 14: 112-114.

Hundal, J. S., Singh, U., Singh, N., Kansal, S. K. and Bhatti, J. S. 2016. Impact of training knowledge on goat farmers of Punjab. Haryana Vet. 55:47-49.

Landge, S. 2004. Study of goat production practices by goat keepers of Kandhar block in Nanded district. M.V.Sc. Thesis, MAFSU, Nagpur.

Mandavkar, P. M., Hanmante, A. A. and Talathi, M. S. 2015. Status of Goat Farming Practices, Knowledge and Adoption Status of Technologies in North Konkan Coastal Zone of Maharashtra J. Krishi Vigyan 3: 93-96.

Mohan, B., Sagar, R. L. and Singh, K. 2009.

Factors related to promotion of scientific goat rearing. Indian Res. J. Ext. Edu. 9: 47-50.

Noor, K. B. N. and Doha, K. 2011. Investigating training impact on farmer's perception and performance. Int. J. Humanit. Soc. Sci. 1(6): 145-152.

Patil, A.P., Gawande, S.H., Gobode, M.R. and Nande, M.D. 2009. Training needs of dairy farmers in Nagpur district. Vet. World, 2(5): 187-190 
Senthilkumar, K., Daisy, M., Kumaravel, V. and Mohan, V. 2014. Impact of KVK training on scientific method of Goat rearing and feeding management of Azolla. Int. J. Sci. Environ. Technol. 3 (06): 2287-2292.

Singh, H. 2012. Training and development: A prominent determinant for improving HR productivity. International Conference on Management and Education Innovation IPEDR, Vol.37 IACSIT Press, Singapore.

Singh, K., Kasrija, R., Singh, B., Sharma, M., Singh, R. and Verma, H. K. 2018. Specialized goat training programme on knowledge level and adoption. Indian Vet. J. 95 (03):30-32.

Singh, K., Kasrija, R., Singh, R., Singh, B., Kansal, S. K. and Verma, H. K. 2019. Specialized Goat Training Programme as an extension tool for Knowledge increment and Adoption. Ruminant Sci. 8(1): 65-67.

Vidya, P., Manivannan, N.K. and Sudeep, K. 2010. The effectiveness of an educational interactive video-DVD on dairy health management practices in terms of knowledge gain among dairy farmers. J. Rural Res. Policy 5(7): 4549.

\section{How to cite this article:}

Khushpreet Singh, Ravdeep Singh, Rajesh Kasrija, Kulvinder Singh, S. K. Kansal and Verma, H. K. 2020. Impact of Specialized Goat Training Programme on Knowledge Level of Farmers A Review. Int.J.Curr.Microbiol.App.Sci. 9(06): 2582-2586.

doi: https://doi.org/10.20546/ijcmas.2020.906.314 